\title{
Stabilization of residual soil with rice husk ash and cement
}

\author{
E.A. Basha, R. Hashim , H.B. Mahmud, A.S. Muntohar
}

Stabilized soil is, in general, a composite material that results from combination and optimization of properties in individual constituent materials. Well-established techniques of soil stabilization are often used to obtain geotechnical materials improved through the addition into soil of such cementing agents as Portland cement, lime, asphalt, etc. Replacement of natural soils, aggregates, and cement with solid industrial by-product is highly desirable. In some cases, a by-product is inferior to traditional earthen materials. Due to its lower cost, however, it makes an attractive alternative if adequate performance can be obtained. In other cases, a by-product may have attributes superior to those of traditional earthen materials. Often selected materials are added to industrial by-products to generate a material with well-controlled and superior properties.

Investigators such as Gidley and Sack [1] proposed several methods for utilizing some industrial wastes in engineering construction. Other studies examined the possibility of improving soil properties such as increasing shear strength, reducing settlement, and minimizing swelling problems by using solid waste. Kamon and Nontananandh [2] combined industrial waste with lime to stabilize soil. Attom and Al-Sharif [3] evaluated burned olive waste for use as soil stabilizer, which is a partial solution to the problems associated with the increase of olive waste in Jordan.

For a given country, in the application of principles of soil stabilization developed elsewhere, an understanding of local conditions is of paramount importance [4]. The soil found locally, in a place, may differ in imperative aspects from soils tested in others. Soil type and climatic conditions affect the characteristics of stabilized soil materials as well as technical method and procedures. The rate of curing may proceed rapidly at higher temperature [5] and rain may affect the compaction and strength of stabilized soil. Residual soils are typical materials of the rural areas in Malaysia, e.g. applied to road and embankment construction. The residual soils in their natural state are suitable for subbase at least, but not for the standard pavement base material [6].

In the agricultural countries, there are problems with abundance of agriculture wastes. Those plants obtain various minerals and silicates from earth in their bodies 
during growth process. Inorganic materials, especially silicates, are found in higher proportions in annually grown plants than in the long-lived trees. Rice, wheat, sunflower, and tobacco plants therefore contain higher amounts of silica in their cuticle parts. Inorganic materials are found in the forms of free salts and particles of cationic groups combined with the anionic groups of the fibres into the plants [7]. The result of burning organic materials is called thermal decomposition. The ash produced in this way is ground to a fine size and mixed with lime in order to obtain a material with a binding characteristic. The quality of this material depends on burning time, temperature, cooling time, and grinding conditions $[8,9]$. The primary objective of this study is to examine the potential of burnt agricultural by-product, rice husk, as a material for stabilising soil. The effects on the consistency, density, and strength of residual soil are studied.

\section{Experimental investigation}

Materials used

Soils

Residual granite soil, which is a typical residual soil in Malaysia, is used in this study. Table 1 presents the properties of the soil, while Fig. 1 shows the diffractograph of the residual soil. Kaolinite clay mineral is identified in the residual soil by a strong diffraction line at $3.57 \mathrm{~A}^{\circ}$, which disappeared when the clay is heated up to 550 _C.

Rice husk ash

Rice husk was considered as valueless by-product of rice milling. At the mills, disposal of the hulls is achieved by burning them in heaps near the mills. Even though, the ashes have been potential pozzolanic materials suitable for use in lime-pozzolana mixes and for portland cements replacement [10]. The ashes used in this study are obtained from burning of rice husk in the incinerator. The properties of the ashes are tabulated in Table 2

\section{Cement}

The cement used is ordinary portland cement. The physical and chemical properties of the cement are given in Table 2.

Laboratory tests

Atterberg limits tests

The Atterberg consistency limits were determined in accordance with the British Standard methods - BS 1377: Part 2 [11]. The residual soil was sieved through $425 \mathrm{~mm}$. Materials that retained on that sieve were rejected for this test. The soils, then, were oven-dried for at least $2 \mathrm{~h}$ before the test. The tests were carried out 
on the soils with different proportion of cement and rice

husk ash (RHA).

Full text available at :

http://ac.els-cdn.com/S0950061804001734/1-s2.0-S0950061804001734-main.pdf? tid=1864bf2a-66e4-11e3-

b575-00000aacb35e\&acdnat $=1387261740 \_$f0d281b7ab2e8395f6d7a56ac5b0bf42

http://www.sciencedirect.com/science/article/pii/S0950061804001734 